\title{
The Magnification Effects of Intra-firm Trade of Multinational Corporations
}

\author{
Lian Lina (Corresponding author) \\ School of Economics, Northwest University for Nationalities \\ Associate professor, PO box 730124 Lanzhou, P.R. China \\ Tel: +86-135-196-30171Ｅ-mail: jjlln@xbmu.edu.cn \\ Ma Haiying \\ School of Economics, Northwest University for Nationalities \\ Lecturer, PO box 730124 Lanzhou, P.R. China \\ Tel: +86-156-931-13831Ｅ-mail: lxmahaiying8888@163.com
}

Received: April 25, 2011 Accepted: July 19, 2011 doi:10.5430/ijba.v2n3p94

\begin{abstract}
:
The 2008 financial crisis and the credit crunch severely restrict the ability of multinational companies to invest abroad and finance cross-boarder mergers and acquisitions; yet do not impair the intra-firm trade among parent firms, subsidiaries and branches. Intra-firm trade is a complement of foreign direct investment whether it is a market-access based FDI or for considerations of factor price differential motivations. Compared with arm's length transactions, intra-firm trade of MNCs is highly contributable to unit the global-based affiliates under one set of rationales of operation mechanism, thus reel off the substantial benefits produced within the boundaries of the host nations. The essay starts with characteristics and incentives of intra-firm trade of MNCs, then analyzes in great details the related effects from the standpoints of international trade structure, international relations and the economy perspectives of the host countries. The author concludes that the sales of affiliates of multinational firms have long dwarfed the value of FDI injection to the host countries and the transfer price system is often illegally used for tax evasion purposes, thus shortchanging the earnings of the host nations. The author proposes corresponding countermeasures by the end.
\end{abstract}

Keywords: Multinational corporations, Intra-firm trade, Arm’s length transactions

\section{Introduction}

As supported by some empirical studies, it is possible that both FDI and economic growth are independent and could lead to two-way causality. On one hand, FDI inflows may promote economic growth of the host country through positive direct effects and spillover effects. On the other hand, countries with rapid economic growth can provide better opportunities to attract greater volume of FDI, as well as generate more demand for FDI. Multinational companies are the concrete existence of FDI, which have long undertaken philanthropic work particularly in the form of donating money, and lending skilled workers to local communities.

From as early as 1980s when the Multinational companies sprout to the economic stage till the recent years, MNCs always do a great deal of arms-length trade, and intra-firm trade as well. Based on the advanced technology, managerial expertise, sufficient capital reserves, experienced and versatile talents, the MNCs hover to the core powers of the increasing international economic integration, and reel off the substantial benefits there-from. The intra-firm trade is highly contributable to this rosy consideration as uniting the global-based affiliates under one set of rationales of operation mechanism. The case studies of many research papers show FDI inflows are proportionately related to the trade volume of the host countries. The bigger share of the FDI in the economic incentives, the larger the exports, and consequently, the further the intra-firm trade sunk in. Intra-firm trade, as a byproduct of FDI and multinational operation commencing from as early as $1860 \mathrm{~s}$, accounts for the majority of the worldwide international trade. According to the statistical data of the Ministry of Commerce of China, in 1970, 90\% of the global oil trade was dominated by 15 well-established multinational corporations, and the consumption was totally conducted beyond the country-of-production. In 1986, 75\% of the Japan imports were offered by the Japanese companies based in other countries (Note 1). In 1987, European Union country firms exported US\$283 billion in products to the United States. In 
the same year, affiliates of EU-based multinational firms sold US\$816 worth of products in the United States, about 3 times the value of exports. Similarly, in 1988, 53\% of the America imports were provided by the U.S.-owned subsidiaries abroad. This figure soared up over $70 \%$ since $1990 \mathrm{~s}$, and around $80 \%$ nowadays (Note 2). The first section of the essay encompasses characteristics and incentives of intra-firm trade of MNCs. Section two outlines in great details the related effects from the standpoints of international trade structure, international relations and the economy perspectives of the host countries. Section three sketches some conclusions that the sales of affiliates of multinational firms have long dwarfed the value of FDI injection to the host countries, thus needs further administration.

\section{Literature Review}

Despite the importance of the issue, a limited profile is evident in the literatures on the negative effects of intra-firm trade of multinational corporations in the international arena with particular attention to the developing host countries until recent years. In as early as April 2004, Ashok Deo Bardhan reports his conclusions of research papers that foreign outsourcing and off-shoring in manufacturing is typical for intra-firm trade of multinational firms. Peter C. Dawson in his research paper Optimal Negotiated Transfer Pricing: MNCs Tangible and Intangible Intra-firm Trade points out that MNCs have a greater incentive to practice abusive transfer pricing for intangibles than tangibles. Kimberly A. Clausing undertakes an empirical investigation through a gravity equation model. He concludes in his CEPS working document that it will be difficult for policymakers and forecasters to predict how intra-firm trade of multinational firms will respond to changes in the economic or policy environment. Shujiro Urata in his February 2006 research paper International Intra-firm Transfer of Technology for Japanese Corporations touches the question of technology transfer and figures out the underlying importance of providing FDI friendly environment and improving the quality of human resources. In February 2008, Andrew B. Bernard examines the determinants of intra-firm trade in U.S. imports and confines the findings that intra-firm trade is high for products with low levels of contractibility sourced from countries with weak governance, for skill-intensive products from skill-scarce countries, and for capital-intensive goods from capital- abundant countries. In the same year, Stephen Ross Yeaple in his research paper Firm Heterogeneity, Intra-firm Trade, the Role of Central Locations demonstrates three forms of FDI as export FDI, centralized FDI, and decentralized FDI which may induce the intra-firm trade of MNCs as to concentrate the production of some of the intermediate inputs in the centralized country thus engage in intra-firm trade thereof. A long list of other scholars address this question in the international arena or from the perspectives of a certain country or a specific industry, such as David Greenaway, peter Lloyd, Chris Milner, William J. Zeile, Peter C. Dawson, Stephen M. Miller, Peter Egger, Michael Pfaffermayr, DR. Axle Grioud etc.

Some Chinese scholars declares their eagerness in their essays of Chinese versions in various aspects as threats of national security in terms of intra-firm trade of multinational enterprises, the underlying squeezing-out of the domestic industries development, the possible monopolistic prospects by foreign affiliates, and the countermeasures feasible for tax authorities to ward off the profit leakage and so on.

The typical features of the essay are, based on the well probe into many research papers both in English versions and in Chinese versions, to sketch out that intra-firm trade differs from conventional trade conducted at arms-length from several perspectives. International trade utilizes consumer and producer where the trade flows between two countries depend on numerous factors as country income, distance, culture similarity, pricing policy and exchange rate variables etc. And what's more, such trade is hypothesized to depend positively on the economic size of the trading partners, whether in the criteria of GDP of the two countries or their GDP per capita. Yet the above-mentioned general deduction can't offer answers to the fact that why some nations trade more than average with each other and less than average with the others even though there exist no obvious foundations for international exchange of goods or services, and there should be something beyond the traditional theories as factor endowment philosophy or Heckscher-Ohlin rationale. This is an open question and the key question of the paper that intra-firm trade may explain the gaps from at least three senses: (1) it is more sensitive to tax influences (2) it is less responsive to economic change of the host nations (3) it is more likely to be trade in intermediate products. With respect to lack of data from MNCs as to the percentage of intra-firm trade or earnings generated there-from, the paper has a comparatively less explanatory power.

\section{Characteristics and Incentives of Intra-firm Trade}

Intra-firm trade is international trade that occurs between different affiliates of the same multinational firm. The dealings may involve tangibles, intangibles, or technological know-hows and patents either in a bilateral way as between the parent company and its subsidiaries, or between subsidiaries and branches, or in a multilateral ways covering more than two entities of the same MNC. Intra-firm trade behaves quite differently from trade between unaffiliated entities with several respects such as key economic variables, such as GDP growth, income per-capita, exchange rate, distance between trading partners and cultural proximity etc. 


\subsection{Characteristics of Intra-firm Trade}

\subsubsection{The Manufactured Goods are the Core of MNCs Intra-firm Trade, Followed by Intangibles}

FDI is the mainstream of lures for multinational corporations to establish foothold operations in the host countries or regions, thus entitle the MNCs to screen the location of externality-rich economic activities anywhere as their affiliates being based in. In the e-commerce era, MNCs have networks that enable them to better cope with imperfect information across international boundary, so most of multinational corporations can strategically locate a fragment of its production activity in the source country, an activity that is absolutely being motivated by huge energy and resources inputs. Generally speaking, the degree and frequency of Intra-firm trade of multinational corporations deepens along with the processing chain of the commodities. The manufactured goods enjoy a higher share of Intra-firm trade than both the initial stage of raw material collection and the semi-finished goods supply.

As being evidenced by many research papers, a large portion of international trade occurs through intra-firm transfers, with an increasing portion involving intangible assets. Most practitioners know the determination of the arm's length range for tangible goods is fairly concrete and measurable, while the lack of access to privately kept license agreement for licensed intangibles makes the estimated arm's length standard for intangibles less reliable and uncontrollable, and thus offers greater potential for transfer price abuses. The arm's length criteria for the royalty rate proves more difficult to estimate, therefore it is subject to be a lure for intra-firm intangibles transactions thus to maximize world-wide after-tax profits for multinational corporation as a whole.

\subsubsection{The Title of Goods Do Not Transfer Along with the Hand-over}

The intra-firm trade is undoubtedly a special form of international trade, but it's typically a kind of transaction under one roof of a multinational firm and proceeds with different subsidiaries and branches. So the ownership to the goods or services in question belongs to this specific multinational firm, no matter how substantial the order may hint for the export or import of the foreign makes. It tells no differentiation as whether the global linkage exists in forms of joint ventures, wholly-owned subsidiary, or just in an implicit consolidation in technology know-hows or managerial expertise.

\subsubsection{The Strategically Set Global Operation Mechanism is the Requirement of Intra-firm Trade}

What masks important difference of intra-firm trade with the conventional trade---the arm-length transaction is the binding requirement of each case. Whenever or wherever or the amount of the contract value the intra-firm trade may be concluded shall be determined by the global operation mechanism of the multinational firm, and at the level of transfer price rather than at arm's length in an external market. The operation strategy of the MNC headquarters creates goal congruence of all the subsidiaries, branches and the parent company.

\subsection{The Structure of Intra-firm Trade}

\subsubsection{The Sector Structure of Intra-firm Trade}

According to the data of research papers of Donning, the percentage of the internal exportation trade of the parent company differs greatly in sectors, say, $91.3 \%$ in computer, $51 \%$ in oil industry, $62.4 \%$ in auto industry, $36.5 \%$ in electronic appliances, $12.8 \%$ in textiles and $9.8 \%$ in foodstuff processing. We may conclude that the intra-firm trade clusters around the technology-intensive sectors for the underlying reasons that the implicit or explicit global advantages of the multinational firm derived from the technological competitiveness and cost effectiveness of these sectors natured through long history of development. In the labor-intensive sectors, the intra-firm trade of MNCs is not so outshining. Indeed, some FDI may involve no addition to the capital stock of the host country but purely the introduction of an improved technology into the desired sphere. This may not necessarily lead to technology transfer, if the secrets of the technology remain with the acquiring firm and keep in the hands of its source-country personnel. But the technology will still be applied to manufacturing proceedings in the host country and increase the output. This highlights the idea that the shinning halo of MNCs to the host governments is their advanced technique expertise, thus what are desirous by the host countries for the entry of MNCs are as broad as the state and appropriateness of available technology, transfer of skills, extent of research\& development etc. The intra-firm trade makes the host governments soon disillusioned for the core technology is limitedly transfused between the branch members of MNCs and can well fence off the technological spillovers and model copying innovation. Nowadays, the multinational firms monopolize $70 \%$ of technique transfer and $80 \%$ of new technology, and around $80 \%$ of royalties in technology licensing and franchising were affected in the form of intra-firm trade of MNCs (Note 3). 


\subsubsection{The Regional Structure of Intra-firm Trade}

The regional structure refers to the geographic distribution of intra-firm trade. Drawing on business-oriented analysis and the econometric studies, there appears to be consensus that the more advanced the economy develops, the higher ratio of intra-firm trade shall occupy. Much of the intra-firm trade was concentrated to the economy developed countries or regions. The Europe Union, the Free Trade Zone of North America, and the APEC are exercising mature liberalization of trade and capital flows, combined with the huge round-tripped investment; consequently the intra-firm trade takes up a considerable share.

\subsection{The Incentives of Intra-firm Trade}

\subsubsection{Cost Reduction, Thus to Shade from Uncertainties of the External Market}

In international trade, cost may be accrued from several perspectives. Firstly, surcharges would occur due to staggering time for perfect information with the seller cherishing much more than the perspective buyers, then further accumulated by the malfunction of pricing mechanism. Secondly, profit maximization is the common goal for either the seller or the buyer in a possible international transaction. Both of them will seek for business partnership through all available channels, undergo lengthy on-and-off bargaining and finally conclude the transaction. This process will definitely induce cost. Last, the external market uncertainty will strengthen the extraordinary payment with a long list as the government interference, the protectionism measurements and the following conciliations etc. The intra-firm trade can alleviate these absurd headaches for the comparatively mild trade barriers of business partners as compared with those of the unaffiliated countries, thus may launch for monopolistic market share.

\subsubsection{The Scrutiny of Transfer Price in Intra-firm Trade}

The abusive transfer price practices create substantial opportunities for MNCs to shift profits earned in high-tax countries to related affiliated entities or divisions in low-tax countries or even tax heavens. When a department within a multinational firm transfers its tangible or intangible output to another department or a subsidiary, we may regard this transfer as a sale. The price that is placed on such products, services, and technology know-how is generally regarded as the transfer price, or TP as normally abbreviated. Whether the parent company will choose a low or high TP do not depend upon the law of supply of the market but upon country-of-entry tax rate related to the home country. When the tax rate is low relative to the host country, the MNC-owned foreign-based affiliates should buy low and sell high, accruing majority of the profits in the low tax rate country and increase the profit margin of the MNCs as a whole. Say, the income tax rate for domestic-residing firms in general is $25 \%$, the rival foreign firms usually are entertained with many preferential treats and exemptions, especially for those pinpoint in the economic zone the taxation rate is possibly as low as $15 \%$ (Note 4). The difference in the tax practice of countries makes it feasible for profit-shift business conducts. What's more, the multinational firms may have incentives to overprice or under-price the goods or services sold to high tax affiliates in views of tax considerations.

\subsubsection{The Inclination to Trust Union and the Worldwide Monopolistic Position}

The multinational corporations may cultivate the proposed collaborative relationship with the various host countries as in the ways of promoting market integration, diversifying market supplies, and exercising as strong backbones for the money injections of the economy appetites. The MNCs would rather control a host business or entity engaged in interstate commerce participating in or acting on behalf of its foreign counterparts. The local firms warrant the availability of off-the-shelf inputs of raw materials, the parts\& components, and intermediate goods to revitalize the production, assembling or processing activities of a MNC. Yet, this does not open a channel for leakage of unique techniques. This is likely to doom that the host companies only get an access non-credible or transfer of technology inconsequential, and every critical or essential sector are kept in the hands of home-country citizens or businesses, thus consolidate the monopolistic image of a multinational firm.

\section{The Negative Effects of Intra-firm Trade of Multinational Corporations}

\subsection{From the Perspective of International Trade Structure and Order}

The intra-firm trade may trigger a magnificent change of international trade structure. On one hand, the increasing intra-firm trade has squeezed out the share of arms length transactions in the global arena, as it has split the trade possibilities into two and make them offset in their powers and advantages. The law of survival of the fittest has been deteriorated since the intra-firm trade of MNCs may appear to involve lower values than the real dealing may generate, and hence depress the share price- the value of the multinational firms as a whole. On the other hand, the intra-firm trade has huge impact on the structure of international exports and imports. Ordinarily, tangibles are transacted more frequently in international trade than intangibles with primary goods taking up a bigger share than the manufactured 
goods. Yet this has evolved into a new phase of intra-firm trade with the intermediate goods and manufactured commodities soaring up and technical and service trade manifesting key position.

\subsection{From the Perspective of International Trade Pricing Mechanism}

The multinational firms usually set the transfer price arbitrarily by using a method of cost-plus and sometimes percentage for contingencies, which can often reflect market and competitive dynamics, cost and profit objectives, or resource allocation decisions of MNCs. The price maker of the TP is the management in the headquarter offices based on the scrutiny of tax or non-tax related criteria, with harmonization of intent between parent companies, subsidiaries and branches. Once a decision is made, the TP policy will be formally defined, clearly communicated to all participators under complete currency or profit manipulation. This procedure may even successfully entice the parent company to order a remote subsidiary to repatriate earnings to shore up balance sheets. The international trade pricing mechanism does not function in the concrete inflows and outflows of both the goods and the capitals as well, and lead to an unfair trading relationship within the MNCs and the unaffiliated countries. Further more, the disequilibrium of the benefits derived from world trade in the globalization process may be deepened and countries with well-established financial markets in wherever their business may cover gain significantly from FDI and MNCs performances.

\subsection{From the Perspective of International Relations}

The transfer price manipulation has pinned the intra-firm trade down on profit maximization that can expedite the multinational firms to fit into global supply chain, and determine their outsourcing destinations more efficiently. While the host country has been thrown into a dilemma of enshrining foreign inhabitants to meet its economy appetite, it has being tortured by the backlash of huge loss on the balance sheets of the foreign affiliates. The foreign-controlled firms in one industry could also influence positively production performance of the upstream and downstream industries in host countries via the inter-industry linkages. What makes things depressed is the re-export of the finished goods ready for sale as the assembly line yield the technological-embedded output ready for sale, and the original host country is always the most preferred target destination. The repatriation of the profits and the following re-investment push the situation to an even worse situation for the high complexity of cash flows and the volatile balance sheets. The host country, in most cases, is completely out of control for the deteriorating international payment, and if possible he may exert diplomatic pressures on its trade partners. This leads to a further chaos in a new sphere and does not generate optimistic results as expected. The treacherous intra-firm trade can still lend a lame excuse for some multinational firms to allege for easier access to resources or privileges for the superficial loss of the financial sheet, though everybody knows such assets and liabilities balance do not cover all the earning ledgers.

\subsection{From the Perspective of the Host Country}

Most of the well-established multinational corporations are from advanced industrialized economies. The era of globalization gives them good opportunities to perform worldwide operation and reap maximal returns. This may pose more pressures and challenges to the developing countries and the less developed nations, with some of them being chosen as target host countries thus facing fresh problems. Firstly, the foreign-owned local-based MNCs may forward severe requirements or privileges as related to the resources access or the tax policies that will facilitate their operations in the host country. Secondly, the MNCs may take the reins of the local firms, and as suggested by the statistics data, make them engaged in export-intensive manufacturing by performing labor-intensive operations on imported goods for re-export as OEM alleged loudly. The development agenda of MNCs is not well integrated into mainstream economy of the host country. Through the efficient use of intra-firm trade, the MNCs can develop the kind of vertical integration across boarders and exercise a fragmented nature of production. Throughout the world, the high-tech value chain is now both multilateral and multinational, involving many countries but often just one firm or a group of affiliated firms.

\subsubsection{The Transfer Price may Cloud the Interests of the Host Country}

Transfer price creates key tricks for the foreign outsourcing of intermediate inputs of multinational firms. Usually, the FDI inflow is an offshoot of rich raw materials, comparatively cheap labor force, the great market potentiality, or the favorable investment incentives. The shining halo of capital injection of MNCs eclipses the accompanied intra-firm trade for the tax evasion purpose, and the capital inflows or outflows as being manipulated by the MNCs headquarters. The cute employment of transfer price in the multinational family makes the interests of the host country impaired for loss of part of the earning produced at home, and the uncontrollably shaking finance markets as well.

\subsubsection{The Intra-firm Trade may Harness the Industry Linkage Effects of the Host Country}

The industry linkage effects refer to the development of an industry segment may trigger the inducement of the related upstream or downstream industries to spur at a certain extent. This is usually the case in the development agenda of the correlated sectors of a nation alone. Now if the MNCs come onto the stage, the paradoxical result may occur. The 
low-cost foreign outsourcing has long attracted many firms to participate in, whether as a part of multinational enterprise, or acting as independent companies in the host countries. For various considerations as preferential tax levies, guaranteed quality, or merely the operation strategy of the MNCs, the local production firms engaging in assembling or processing are motivated to use imported inputs from affiliates abroad, instead of inputs from arm's length domestic manufacturers. This will definitely undermine the linkage spillovers as what is desirous in the FDI inflows. What's more, the MNCs usually pinpoint some of its production activities in the source country that requires huge energy and resources inputs. This will expedite many new issues such as deforestation, spoiled ecosystems, illegal dumping of industrial wastes, chemical incidents, plausible exertion of raw materials, and non-point source biological pollution of rivers etc.

\section{Conclusions:}

For many countries, the sales of affiliates of multinational firms have long dwarfed the value of trade, especially from the perspectives of host countries. The transfer price system is often illegally used for tax evasion purposes, thus shortchanging the earnings of the host nations. Since the FDI spillovers can not, in all probabilities, be easily disentangled from its economic cohesions, all the nations with the developing countries and less developed countries in particular should be extremely cautious with the intra-firm trade of multinational enterprises for it can tactically skim off the partial profits produced within the boundaries.

\subsection{Set Basic Arm's Length Standard and Warrant the Enforcement}

International investment agreement set ground rules for how host government trust foreign investors prerequisite for benchmark of the Basic Arm's Length Standard criterion, which championed by the United States has now been accepted worldwide as the preferred standard by which transfer price should be set. The local tax authority looks into the comparable selling prices set by independent buyers and sellers in similar transaction environment, and this level becomes the BALS benchmark to justify the cross boarder trade between the affiliates of a multinational corporation.

In practice, for given the incentives to exercise transfer pricing abuse, when a MNC perceives the arm's length range as a guideline rather than a strict constraint, the likelihood of abuse may increase as to estimate the probability of a tax auditing and the potential tax savings while deciding if, or by how much, to violate the arm's length criterion. So the tax authorities of the host nations should enforce the BALS benchmark as a binding constraint of all the foreign inhabitants. To audit as much as the intra-firm transactions, specifically the tax and performance evaluation disconnected from transfer price urge the requirement of investing greater resources to train tax audit specialists for quick and correct identification of the TP abuses.

\subsection{Screen the FDI Access and Acquire the Negotiated Transfer Price}

To promulgate code of conduct for multinational firms will partially lessen the implied threats from the intra-firm trade of MNCs. This may simply focus on the certification of eligibility for the FDI access. For example, a foreign organization is trying to limit its contributions to mere cash donations or occasional charitable giving is immediately crossed off in the list of potential incomers.

Furthermore, the governments of the host nations, the developing and less developed countries in particular, should cement and wield their bargaining powers to acquire the negotiated transfer price, which may be based on the tax reports, contract value, the execution span of the transaction, and as for the intangibles intra-firm trade, annual patent fees, royalty base, licensee sales revenues etc. The negotiated transfer price may lie within the arm’s length boundary, and most importantly, to harness the MNCs to adopt a fairer mechanism to allocate the joint gain as to be consistent with the equilibrium transfer price. 


\section{References}

Clausing, Kimberly A (1998). The impact of transfer pricing on intra-firm trade. NBER working paper no.6688, forthcoming within $\mathrm{U}$ of Chicago Press volume

Dawson, Peter C. (1999). Transfer price determination in a multinational corporation: decentralized decision-making, agency costs, and strategic interaction. Ph. D. Dissertation, the University of Connecticut

Urata, Shujiro (1999). Intra-firm technology transfer by Japanese multinationals in Asia. In Dennis J. Encarnation (Eds.), Japanese Multinationals in Asia: Regional Operations in Comparative Perspective. New York. Oxford University Press. P120-156

Encarnation, Dennis (1994). Intra-firm trade in North America and the European Community. In Eden, Lorraine, ed. Multinationals in North America. Calgary: Vof Calgary. P309-334

Konrad Kai A. \& Lommerud Kjell Erik (2002). Foreign direct investment, intra-firm trade and ownership structure, Retrieved from http:// google.com.hk/ intra-firm trade of MNCs

Vaysman, Igor (1998). A model of negotiated transfer pricing. Journal of Accounting and Economics 25: 349-384

Grubert, H. (2003). Intangible income, inter-company transactions, income shifting, and the choice of location. National Tax Journal 56, P221-242

Clausing, Kimberly A (2003). Tax-motivated transfer pricing and US intra-firm trade prices, Journal of Public Economics 87, P2207-2223

\section{Notes}

Note 1. http://www. bjreview. Com, TNC Internal Trade ( in Chinese)

Note 2. Kimberly A. Clausing, CEPS Working Document, the intra-firm trade of multinational firms: the empirical behavior of intra-firm trade in a gravity equation model

Note 3. http://www. bjreview. Com, TNC Internal Trade ( in Chinese)

Note 4. The Tax Law, The Chinese Institute of Certified Public Accountants , Beijing: Economic Science Press, First Edition, p326-386 